\title{
Lipoperoxidation and Aflatoxin Biosynthesis by Aspergillus parasiticus and A. flavus
}

\author{
By A. A. FABBRI, ${ }^{1 *}$ C. FANELli, ${ }^{1}$ G. PANFILI, ${ }^{1}$ S. PASSI ${ }^{2}$ AND \\ P. FASELLA ${ }^{3}$ \\ ${ }^{1}$ Dipartimento di Biologia vegetale, Università di Roma 'La Sapienza', Largo Cristina di \\ Svezia 24, 00165 Roma, Italy \\ ${ }^{2}$ Istituto S. Gallicano, Via S. Gallicano, Roma, Italy \\ ${ }^{3}$ Cattedra di Chimica Biologica, Università di Roma 'Tor Vergata', Roma, Italy
}

(Received 7 March 1983; revised 27 June 1983)

The amount of aflatoxin produced by Aspergillus flavus and Aspergillus parasiticus grown on various aged and non-aged seeds, kept at suitable conditions of temperature and moisture, is particularly related to the peroxide numbers of the seed oils. The addition of synthetic hydroperoxides to the cultures greatly increased aflatoxin production.

\section{INTRODUCTION}

Since aflatoxins were discovered, many experiments have been done to study the biochemical and physical factors affecting aflatoxin biosynthesis when toxigenic strains of Aspergillus flavus or Aspergillus parasiticus grow on different media or substrates (Heathcote \& Hibbert, 1978; Maggon et al., 1977). Also, the influence of the degree of aerobiosis, moisture and humidity (Rodricks, 1976), or traces of zinc, molybdenum and other metals (Lee et al., 1966) have been related to the stimulation of aflatoxin biosynthesis. The production of aflatoxins on agricultural crops like rice, wheat, cotton-seeds, maize, coconuts, soybeans and sunflower seeds is wellknown (Stoloff, 1977), even if available reports show remarkable differences in the amounts of mycotoxins from the different seeds analysed.

In our previous work we found that aflatoxin production by $A$. flavus is much higher on oil seeds than on starchy seeds (Fabbri et al., 1980) and for this reason we tried to determine whether aflatoxin biosynthesis specifically depended on the most important lipid fractions of oil seeds. Liquid culture media of $\boldsymbol{A}$. flavus were supplemented with synthetic triglycerides, fatty acids and sterols, but these lipid fractions acted as carbon sources (Fanelli et al., 1980) promoting the growth of the fungus without enhancing aflatoxin production (Fanelli et al., 1981).

Very recently, however, we have demonstrated that cerulenin and tetrahydrocerulenin, inhibitors of fatty acid synthetase (D'Agnolo et al., 1973), showed a remarkable effect on aflatoxin production when added to culture medium inoculated with $A$. parasiticus, and it was supposed that the effect might be related to their epoxide structure (Fanelli et al., 1983a). This hypothesis was confirmed by our other experiments that showed that lipophilic epoxides $(9,10-$ epoxymethylstearate and 9,10:12,13-diepoxymethylstearate) showed an even greater effect than cerulenin and tetrahydrocerulenin in inducing biosynthesis of aflatoxins (Fanelli et al., 1983 b).

Lipid epoxides may be formed in limited amounts during the oxidation of unsaturated lipids or during the lipoperoxidation which primarily produces lipoperoxides (lipid peroxide radicals, hydroperoxides) and subsequently many other breakdown products responsible for rancidity in naturally occurring fats (Giuliano \& Stein, 1974).

In the present work, synthetic lipoperoxides were added to cultures of $A$. parasiticus and $A$. flavus to see whether they induced aflatoxin production. A range of different seeds, with oils of varying peroxide numbers, were incubated in the presence of different strains of Aspergillus and the aflatoxin production was analysed. 


\section{METHODS}

Fungus culture. Aspergillus parasiticus Speare (strain NRRL 2999) was analysed in this study. In some experiments we also used two toxigenic strains of $A$. flavus Link ex Fr. (strains ATCC 22548 and CF1 isolated in our Institute from wheat seeds stored in silos). Stock cultures were maintained on Czapek Dox agar (Difco) supplemented with $\mathrm{ZnSO}_{4} \cdot 7 \mathrm{H}_{2} \mathrm{O}\left(5 \mathrm{mg} \mathrm{l}^{-1}\right)$ and $\mathrm{Na}_{2} \mathrm{MoO}_{4} \cdot 2 \mathrm{H}_{2} \mathrm{O}\left(1 \mathrm{mg} \mathrm{l}^{-1}\right)$ at $4{ }^{\circ} \mathrm{C}$.

Lipoperoxidation. Linoleic acid $\left(\mathrm{C}_{18: 2(9,12)}\right)$ (Sigma) was peroxidated with lipoxidase (linoleate : oxygen oxidoreductase EC 1.13.11.12) (Sigma) according to Hamberg \& Samuelsson (1965). The peroxidated material was purified by silicic acid chromatography (Hamberg \& Samuelsson, 1965).

Agricultural commodities. Seeds of wheat (Triticum vulgare var. Manitoba), maize (Zea mays var. Decalb 365), peanut (Arachis hypogaea var. Bombay), soybean (Glycine max) and sunflower (Helianthus annuus var. Uniflor 70) of different ages were used. The 'non-aged' seeds were seeds harvested and stored no more than 1-2 months. The different aged seeds were kept in experimental silos in our Institute for up to 3 years without concern for the temperature and humidity of the environment. Fatty acid composition, peroxide number and iodine value were determined according to statutory Italian procedures (Anonymous, 1976).

Culture conditions. Samples containing $10^{6}$ conidia from 15 cultures of A. flavus or A. parasiticus grown on Czapek Dox medium agar were inoculated on the following.

(a) Synthetic culture medium [Czapek Dox broth plus $\mathrm{ZnSO}_{4} \cdot 7 \mathrm{H}_{2} \mathrm{O}\left(5 \mathrm{mg} \mathrm{1^{-1 }}\right.$ ) and $\mathrm{Na}_{2} \mathrm{MoO}_{4} \cdot 2 \mathrm{H}_{2} \mathrm{O}$ $\left(1 \mathrm{mg} \mathrm{l}^{-1}\right)$ ] supplemented with linoleic acid $\left(0.25 \mathrm{mg} \mathrm{m}^{-1}\right.$ or $\left.0.5 \mathrm{mg} \mathrm{ml}^{-1}\right)$ and linoleic acid hydroperoxides $\left(0.25 \mathrm{mg} \mathrm{ml}^{-1}\right.$ or $0.50 \mathrm{mg} \mathrm{ml}^{-1}$; either a non-purified peroxidated linoleic acid mixture or the purified linoleic acid hydroperoxides that consist of about 30\% 9-hydroperoxyoctadeca-10,12-dienoic acid and about 70\% 13 hydroperoxyoctadeca-9,11-dienoic acid). All the experiments were done in $50 \mathrm{ml}$ medium in $100 \mathrm{ml}$ Erlenmeyer flasks at $30^{\circ} \mathrm{C}$.

(b) A $20 \mathrm{~g}$ portion of seeds was moistened with enough sterile water to be suitable for the growth of the fungi (Fabbri et al., 1980); as each seed type had its natural moisture, not always optimal for fungal growth, water was added in order to reach the following moisture values: wheat, $18.5 \%$; maize, $21.7 \%$; sunflower, $11 \%$; peanut $11 \%$, soybean, $15 \%$. The seeds were put in $100 \mathrm{ml}$ Erlenmeyer flasks and autoclaved for $20 \mathrm{~min}$ at $121{ }^{\circ} \mathrm{C}$ after which they were inoculated and incubated at $30^{\circ} \mathrm{C}$. All the analyses of the seeds were made before autoclaving, which does not significantly affect the levels of lipid peroxides, the iodine value and the fatty acid composition. None of the seeds used in our experiments contained aflatoxins before inoculation.

Estimation of fungal growth. Fungal growth was estimated as previously described (Fanelli et al., 1980).

Analysis of aflatoxins. The aflatoxins were extracted and analysed as described by Fanelli et al. (1983a).

Statistics. Data are presented as means \pm S.E.M.

\section{RESULTS}

Table 1 reports the fatty acid composition and the properties of oil extracted from non-aged samples of the seeds studied. The iodine values and peroxide numbers were very variable for aged seeds of all types because very different ages were used, but in all cases analysed in our experiments, the iodine value decreased and the peroxide number increased with age. In one sample of 3-year-old sunflower kernels, we found an iodine value of $118 \pm 4$ and a peroxide number of $17 \pm 1 \cdot 1$. [However, it is not always true that the peroxide number is higher in aged seeds than in non-aged ones; the result may depend on chemical and physical conditions during the storage.]

Table 2 reports aflatoxin production by $A$. parasiticus on non-aged seeds after 15,30 and $40 \mathrm{~d}$ incubation at $30^{\circ} \mathrm{C}$. In the aged seeds analysed in our experiments, which had a higher peroxide number than non-aged ones, the aflatoxin production was much higher. The highest production was detected in a sample of aged sunflower seeds showing, after $30 \mathrm{~d}$ incubation, $3 \cdot 2 \pm 0.4 \mathrm{mg}$ aflatoxins (g seeds) ${ }^{-1}$.

Table 3 reports fungal growth, total lipid content of mycelia and production of aflatoxins by $A$. parasiticus on synthetic media supplemented with different concentrations of linoleic acid $\left(\mathrm{C}_{18: 2(9,12)}\right)$ and peroxidated linoleic acid at 6 and $10 \mathrm{~d}$ incubation at $30^{\circ} \mathrm{C}$. The presence in the cultures of hydroperoxides greatly increased aflatoxin production. The percentage composition of lipid fractions of $\mathrm{CHCl}_{3} / \mathrm{CH}_{3} \mathrm{OH}(2: 1, \mathrm{v} / \mathrm{v})$ extracts from mycelia and the fatty acid composition of free fatty acids, triglycerides and polar lipid fractions were also studied. No significant difference was found among all the samples examined (control mycelium and mycelia from cultures supplemented with peroxidated linoleic acid) either in the percentage composition of lipid fractions or in the fatty acid composition of the different lipid fractions. 


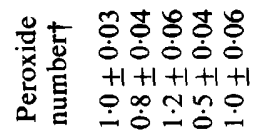

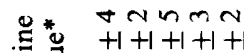

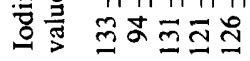

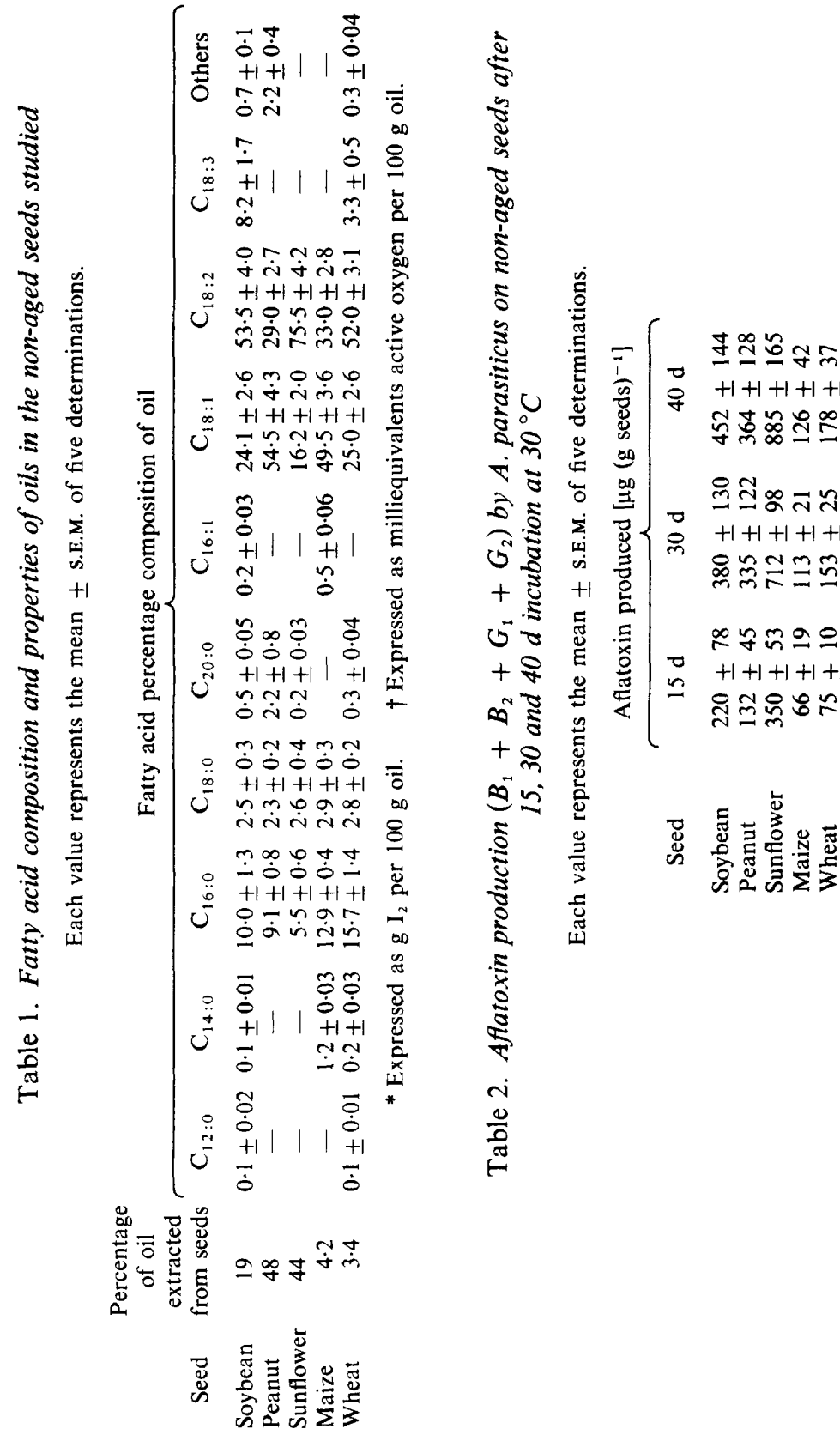




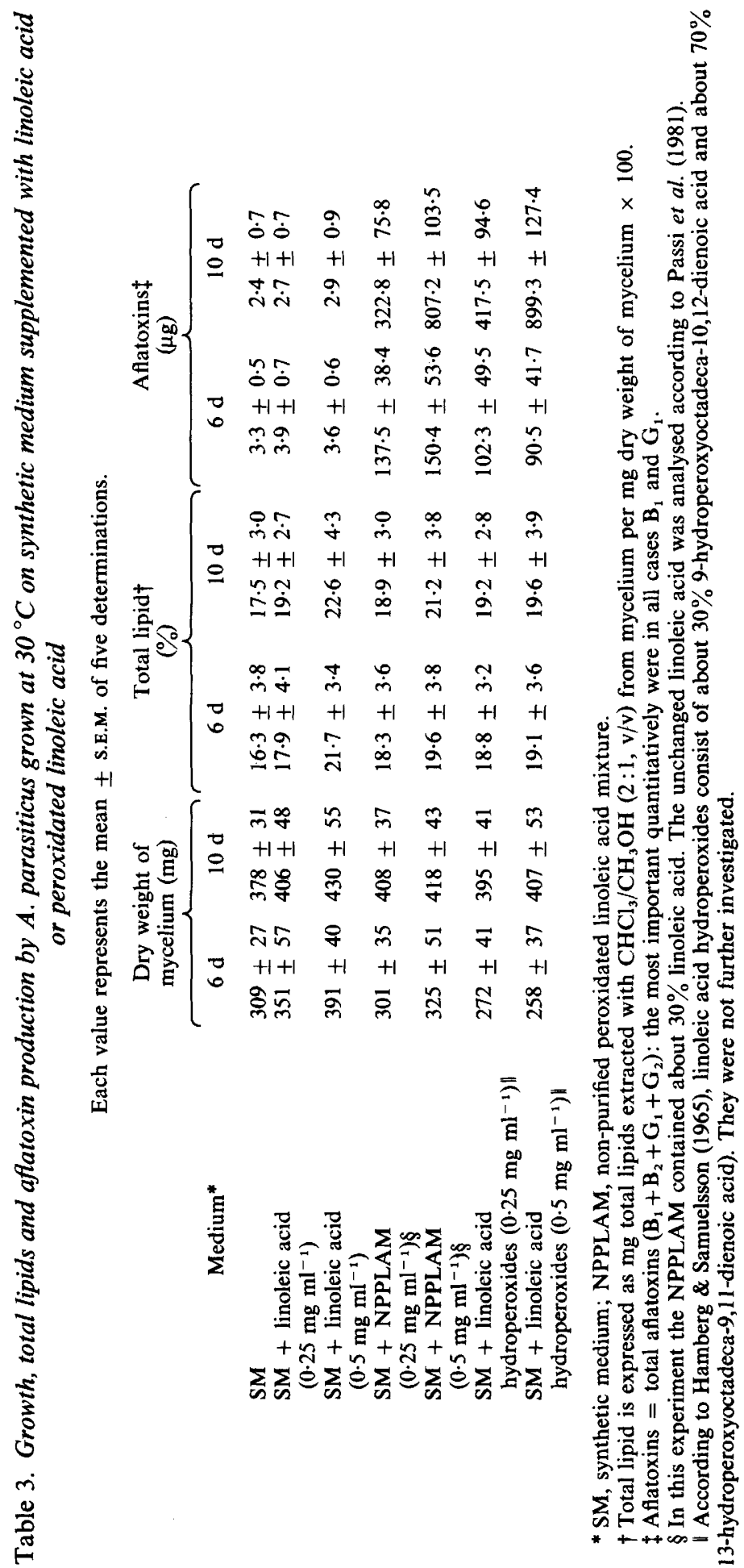


This confirmed our previous work (Fanelli et al., 1983a,b). The experiments carried out with the toxigenic strains of $A$. flavus (ATCC 22548 and CF1) confirmed the stimulation of aflatoxin biosynthesis by hydroperoxides. For example, the two strains of $A$. flavus after $10 \mathrm{~d}$ incubation at $30^{\circ} \mathrm{C}$ on synthetic medium $(50 \mathrm{ml})$ supplemented with non-purified peroxidated linoleic acid mixture (NPPLAM) $\left(0.5 \mathrm{mg} \mathrm{ml}^{-1}\right)$, produced total aflatoxins as follows: strain ATCC 22548 , $651 \cdot 0 \pm 151 \cdot 3 \mu \mathrm{g} ;$ strain $\mathrm{CF} 1,778 \pm 188.2 \mu \mathrm{g}$. In all cases, the quantitatively most important aflatoxins were $B_{1}$ and $G_{1}$.

\section{DISCUSSION}

From our results it appears that the oxidation of unsaturated lipids plays a fundamental role in the induction of aflatoxin production by $A$. flavus and $A$. parasiticus. In previous work (Fanelli $e t$ $a l ., 1983 b$ ) we also demonstrated that synthetic epoxides, at about the same concentration as lipoperoxides, induced aflatoxin production in cultures of $A$. flavus and $A$. parasiticus. But, whereas epoxides may form to a limited extent during the oxidation of unsaturated lipids, both in vivo and in vitro, the main products are lipoperoxides which can undergo further degradation. It is well known that the tendency of unsaturated lipids to absorb oxygen is directly dependent on the degree of unsaturation. In fact, while oxygen uptake is very low in mono-unsaturated lipids, polyunsaturated lipids bind oxygen even at room temperature in daylight. The problem is further complicated by the fact that many other chemical and physical factors in the environment may act on lipoperoxidation: radiation, temperature, humidity and the presence of various metal salts and antioxidants.

The amount of aflatoxins produced by $\boldsymbol{A}$. parasiticus on various non-aged seeds, kept under suitable conditions of temperature and moisture, was higher on oily seeds than on starchy seeds (Table 2). In addition, the percentage of polyunsaturated fatty acids (linoleic and linolenic acid) in the oils was important, probably because these fatty acids are more easily peroxidizable than the mono-unsaturated fatty acids. In fact, sunflower seeds ( $75.5 \%$ of linoleic acid in their oil) and soybean $(53.5 \%$ of linoleic acid and $8.2 \%$ of linolenic acid in their oil) permitted the production of a higher amount of mycotoxins than peanut ( $29 \%$ of linoleic acid). Also in the starchy seeds, aflatoxin production was higher on wheat, which has a greater percentage of polyunsaturated fatty acids (52.3\% of linoleic acid and $3.3 \%$ of linolenic acid) than on maize $(33 \%$ of linoleic acid). The induction of aflatoxin production by lipoperoxides might explain the differing results of many authors on aflatoxin contents in various agricultural products.

This study was supported by Cassa di Risparmio di Roma with the purchase of HPLC apparatus. The authors were supported by funds from the Ministry of Education (40\%) for 1981 and from the Faculty of Science of Rome University 'La Sapienza' for 1981 and 1982.

\section{REFERENCES}

ANONYMOUS (1976). Norme Italiane per il Controllo dei Grassi e Derivati, 3rd edn. Milan: Stazione sperimentale per le industrie degli oli e grassi.

D'Agnolo, G., Rosenberg, I. S., Awaya, J., OMura, S. \& Vagelos, P. R. (1973). Specific inactivation of $\beta$-ketoacyl carrier protein synthetase. Biochimica et biophysica acta 326, 155-166.

Fabbri, A. A., Fanelli, C. \& Serafini, M. (1980). Aflatoxin production on cereals, oil seeds and some organic fractions extracted from sunflower. Rendiconti Atti Accademia Nazionale delle Scienze (detta dei $X L) 98$ (IV), 219-228.

Fanelli, C., Fabbri, A. A. \& Passi, S. (1980). Growth requirements and lipid metabolism of Aspergillus flavus. Transactions of the British Mycological Society 75, 371-375.

Fanelli, C., Fabbri, A. A. \& Passi, S. (1981).
Aflatoxin production by Aspergillus flavus during incubation with lipid sources in culture media. Transactions of the British Mycological Society 77, $416-419$.

Fanelli, C., Fabbri, A. A., Finotti, E., Panfili, G. \& PASSI, S. (1983a). Cerulenin and tetrahydrocerulenin: stimulating factors of aflatoxin biosynthesis. Transactions of the British Mycological Society $\mathbf{8 0}$ (in the Press).

Fanelli, C., Fabbri, A. A., Finotri, E. \& Passi, S. $(1983 b)$. Stimulation of aflatoxin biosynthesis by lipophilic epoxides. Journal of General Microbiology 129, 1721-1723.

Givliano, R. \& Stein, M. L. (1974). Quaderni di Chimica degli Alimenti, vol. 3. Rome: Bulzoni Editore.

HamberG, M. \& Samuelsson, B. (1965). On the 
specificity of the lipoxidase catalyzed oxygenation of unsaturated fatty acids. Biochemical and Biophysical Research Communications 21, 531-536.

HEATHCOTE, J. G. \& HibBerT, J. R. (1978). Aflatoxins: Chemical and Biological Aspects. Amsterdam, Oxford, New York: Elsevier.

Lee, E. G. H., Towsley, P. M. \& Walden, C. C. (1966). Effect of bivalent metals on aflatoxin production in submerged cultures. Journal of Food Science 31, 432-436.

Maggon, K. K., Gupta, S. K. \& VenkitasubraMANIAN, T. A. (1977). Biosynthesis of aflatoxins. Bacteriological Reviews 41, 822-855.
Passi, S., Rothschild-Boros, M. C., Fasella, P., NazZaro-Porro, M. \& Whitehouse, D. (1981). An application of high performance liquid chromatography to analysis of lipids in archaeological samples. Journal of Lipid Research 22, 778-784.

RODRICKS, J. V. (1976). Mycotoxins and Other Related Food Problems. Washington, D.C.: American Chemical Society.

StolofF, L. (1977). Aflatoxins - an overview. In Mycotoxins in Human and Animal Health, pp. 8-28. Edited by J. V. Rodricks, C. W. Hesseltine \& M. A. Mehlman. Park Forest South, Illinois: Pathotox Publishers. 